\title{
Academia Goes Facebook? The Potential of Social Network Sites in the Scholarly Realm
}

\author{
Michael Nentwich and René König
}

\begin{abstract}
This network is the seat of scientific opinion which is not held by any single human brain, but which is split into thousands of different fragments... each of whom endorses the other's opinion at second hand, by relying on the consensual chains which link him to all the others through a sequence of overlapping neighborhoods.
\end{abstract}

—Michael Polanyi (1962) in the Republic of Science

\begin{abstract}
Social network sites (SNS) have not only become a fundamental part of the Web, but also increasingly offer novel communicative and networking possibilities for academia. Following a short presentation of the typical functions of (science-specific) SNS, we firstly present the state of knowledge regarding academic usage practices, both in general purpose SNS and in science-specific SNS. Secondly, we assess potential impacts by addressing identified key issues such as privacy, the role of pseudonymity, and the specific form of informal communication in question. In particular, we focus on the issue of network effects and the challenge of multiple channels, which presents itself as a major hurdle for an effective implementation of SNS in academia. Despite these difficulties, we come to the conclusion that SNS are, in principle, functional for scholarly communication and that they have serious potential within academia.
\end{abstract}

\footnotetext{
M. Nentwich $(\bowtie)$

Institute of Technology Assessment, Austrian Academy of Sciences,

Strohgasse 45/5 1030 Vienna, Austria

e-mail: mnent@oeaw.ac.at

R. König

Institute of Technology Assessment and Systems Analysis, Karlsruhe Institute of Technology, PF 364076021 Karlsruhe, Germany

e-mail: rene.koenig@kit.edu
} 


\section{Introduction}

Starting approximately around the year 2000, a growing number of social network sites (SNS) began populating the Internet, offering novel communicative possibilities; above all they link-up its members and map their offline networks. As this seemed to offer an attractive potential for academic communication as well, from the mid-2000s onwards, with a certain peak in 2007/2008, science-specific SNS also entered the market, both disciplinary-focused ones (like AtmosPeer or Edumeres) and more general examples with increasingly large numbers of members (like ResearchGate, Mendeley, Academia.edu). Most SNS provide a central webbased platform which cannot itself be modified by users. Some services give more options for this, for example Ning, which allows for the design of SNS for specific needs within the framework of the software. Vivo, a US-based science-specific SNS, offers even more flexibility as its software is open source and can be hosted on local servers.

Due to their manifold functions and complexity, various definitions exist of what a SNS constitutes (e.g. Mack et al. 2007; Richter and Koch 2007; Schmidt 2009; Boyd and Ellison 2007; Beer 2008; Fuchs 2009). As SNS have multiple functions, it is difficult to impose a selective definition of these; hence, it depends on the specific definition as to whether a platform will be here counted as a SNS. Following Schmidt (2009), we base our definition for this chapter on the possibility of setting up a sophisticated personal 'profile' with information about oneself, such as interests and activities, within a digital space that can usually only be reached after registration. Starting from this profile, users initiate and entertain social relationships with others, making them explicit through interlinking; the members interact and navigate on the platform, which is basically formed by these networks of 'contacts'. Focusing on the central function of profiles enables us to distinguish SNS from other services: Networking alone is also a characteristic of other platforms that are typically not seen as SNS such as the voice-over-IP service Skype or the microblogging service Twitter. As for the latter, the profiles are minimalist and the timeline of messages, not the profile, is at the center of the platform (see chapter C(Micro)Blogging Science? Notes on Potentials and Constraints of New Forms of Scholarly Communication). Similarly, online reference management platforms are organized around publications (see chapter Reference Management). We observe, however, that also in these other services increasingly SNS-like functions are added, so that the distinction is dynamic and not clear-cut.

Even among the SNS in the narrow sense, there are many differences, in particular when it comes to the available communication tools or how users can configure their profiles. Two core functions are always present: identity management and contact management (cf. Richter and Koch 2007). The profiles mapmore or less in the public domain-the contacts of a person and enable access to further members on various paths, i.e. networking. 
As the technical functionality and target groups vary, we may distinguish different types of SNS: There are variations according to the intended usage forms. In some SNS, private purposes prevail, in others professional fields of application dominate; furthermore, in others private and professional use overlap. Requirements for access also vary: some are open, that is, they only require a simple registration which, in principle, can be done by all Internet users (cf. Richter and Koch 2008). This is the case with many popular SNS. Other platforms offer limited free access, but charge user fees for the full service. However, most platforms are free of charge in order to attract a sufficient audience and paying advertisers (see section "Assessing the Potential Future and Impacts of SNS in Academia" for a discussion of the problems related to such business models). Finally, there are specialized networks that are open only for certain communities, such as a company or research group. The available communication forms vary according to different needs. For example, to nudge someone online is used in a private context, whereas many professional networks offer additional functions such as bibliographic searching (see section "Typical Functions of SNS").

In this chapter we discuss SNS only from the viewpoint of use in academia, based on, but extending the analysis in our book Cyberscience 2.0 (Nentwich and König 2012, pp. 19-50). Following a short overview on types of SNS, their typical functions, academic potential, and observable user practices, we focus on a few key issues that are essential for answering our title question, namely whether academia will indeed "go Facebook", that is, whether future communication among scholars will take place predominantly on these platforms, or even on one single dominant platform. These issues include privacy, the role of pseudonymity, and the specific form of informal communication in question. In particular, we focus on the challenge of multiple channels, which presents itself as a major hurdle for an effective implementation of SNS in academia.

\section{An Overview of Functions, Potential, and Usage Practices}

\section{Typical Functions of SNS}

Various functions and forms of communication are typical for SNS, though not all of them are necessarily available in each individual SNS. Science-specific SNS in particular try to develop technologies which meet the requirements of their particular audience.

1. Profiles: User profiles are digital representations of users and as such the central nodes of SNS. Various kinds of information can be made available to other members in a pre-structured way, from contact information to tracking of user activities. In some SNS it is also possible to have specific profiles for organizations. Thus profiles are like enhanced calling cards of individuals, organizations, and groups. Some SNS experiment with special scores to automatically 
rate user activity on the basis of their activity in the SNS, thereby creating a potential metric for reputation (e.g. RG Score in ResearchGate, see Fig. 1).

2. Communication: The integration of multiple communication channels within one platform is a distinctive feature of SNS, as compared to various other webbased communication tools. Various tools are available in order to communicate with other members: messaging, chatting, discussion forums/groups, microblogging, nudging, videoconferencing, etc.

3. Networking: As networking is one of the basic functions of SNS, all sites offer various tools to promote it: contacts/friends, automated or manual propositions for further contacts, search functions (partly also automated), invitations, bookmarking of profiles, automatically generated requests to welcome new members or propose something or someone to them, and network presentation in various forms.

4. Directing attention: The great variety of opportunities to communicate and network in SNS suggests further tools to establish the relevance of content and to direct the attention of its members towards particular items: current issues on start page, external notifications (via e-mail), and the "Like this" button/ "Share this" function. These data may be used in the future as indicators for relevance, discussed under the label of social search (e.g. Biermann 2010).

5. Groups: All users can found thematic groups. By usually offering the following functions, groups enable the detection of and networking with members with similar interests and they provide a digital environment for discussion and collaboration: discussion forum, file upload, collaborative writing environments, tools to administer participants in events, selective access to groups, passive membership. Sometimes group-like options are labeled differently, e.g. "topics"/“projects" in ResearchGate.

\subsection{8}

\section{RG Score}

\begin{tabular}{|c|c|c|}
\hline $\begin{array}{l}\text { A new way to measure } \\
\text { sciontific reputation. }\end{array}$ & 프 & PUBUCATIONS \\
\hline The RG Score takes allyour & & ANSWERS \\
\hline tosearch and turns it into a & E & QUESTIONS \\
\hline & & FOLLOWERS \\
\hline
\end{tabular}
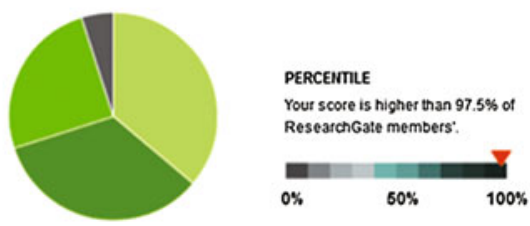

D RG SCORE OVER THE

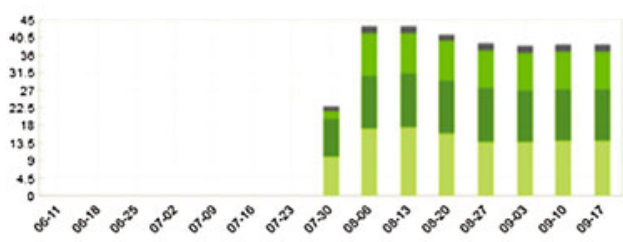

How does the RG Score work?

Your RG Score is calculated based on how other researchers interact whe your content how onen, and who they ate. The higher their score, the more yours will increase.

Fig. 1 Excerpt of an RG score (screenshot) 
6. Calendar: Some SNS offer their users calendars in order to coordinate dates, plan, and market events of all kinds.

7. Literature-related functions: Given the central position of publications in academia, science-specific SNS also offer a number of literature-related functions: searching for academic literature by giving access to other, external, mainly Open-Access databases, as well as internally in the publication lists and database entries of members; similar abstract search; compiling bibliographies; Open Access archive; various attention direction services like notifications, based on topicality, semantic relationships, "Have read" buttons, commenting or rating, "Share this" function, access statistics, and visualization of networks of co-authors.

8. Further services: In addition to these functions, further specialized and targetgroup-specific services are offered: job exchange services, blogging, embedding of services of external providers via apps (thus creating interfaces between the SNS and other services), and advertisement.

Given this broad variety of functions, services, and tools provided by SNS, one is tempted to consider SNS an umbrella for all kinds of features that Cyberscience 2.0 - or Science 2.0-offer to the current and next generations of academics. From a technical point of view, this is a viable assessment. However, this is only a vision which still needs to be realized in practice, given some of the challenges addressed below.

\section{Potentials of SNS for Science and Research}

Our systematic analysis of the potential for academic SNS use starts with the four core areas of scientific activity (Nentwich 2003, p. 24) and reveals that SNS provide functions for all these areas, namely knowledge production, processing and distribution, as well as institutional settings. The various functions of directing attention may be helpful in the process of acquiring information, particularly with regard to literature. Shared data archives potentially help working groups to administer their files. As the multiple possibilities for communication are the core of each SNS, they are, at least from a technical perspective, functional for academic communication as well. Through the various channels, knowledge can be presented and offered for academic discourse. The group functions may support collaboration. However, SNS are not currently an adequate place for publication, even though in principle documents may be published within the network, while access to documents is hampered, as it is usually necessary to register (which also hinders indexing the items in external search-engines). In addition, there is no formalized peer-review process in any of the observed SNS, thus the knowledge distributed via this channel will not be reputable, and less relevant to many. Hence, publication within SNS seem inappropriate at the moment. However, this could potentially change if thorough peer-review mechanisms are established. In 
contrast, SNS may be a valuable additional channel for pointing to texts that have been published elsewhere. They provide a number of functions in that respect: profiles, means of internal communication, tools to direct attention, group functions, and literature-related services. SNS may also be used as e-learning platforms and at the organizational level they are potentially useful as a digital infrastructure. For example, SNS serve as a dynamic list of "digital calling cards" and may help to set up networks of scientists with similar interests as a pool of potential cooperation and communication partners. The popular general-purpose SNS such as Facebook appear especially suitable for public relations, academic organizations such as research institutes, universities, scholarly associations, and networks, as well as for individual researchers.

In line with the multiple services SNS offer, different user practices are conceivable. SNS could serve multilaterally as a discussion forum or as a platform for exchanging information, similar to other web forums and in particular e-mail listservers. Furthermore, they may be used as bilateral communication channels, asynchronously via webmail or synchronously as chatting platforms. SNS may serve as platforms for (micro-)blogging to exchange science-related or day-to-day information, and for e-learning, and one can easily imagine more options for their scholarly application. Thus we note that SNS seem to be functional for a number of essential academic activities.

\section{Academic Usage Practices in SNS}

As of yet, there are only very few, and mostly limited studies of how academics actually use SNS in practice. Therefore, the following account is based both on these few studies and the authors' own experiences and participatory observations over the last few years.

\section{The Diffusion of SNS in Academia and the Intensity of Usage}

The number of members, mostly published by the SNS themselves, and their growth rates is a first indication for the diffusion of SNS in the academic world. ResearchGate, for example, had 150.000 members in August 2008, 700.000 in December 2010, announced a million by May 2011, and reached two million in September 2012. We observed similar growth in other SNS, but the figures may not hold in practice, given their origin. The member count, in any case, does not necessarily correlate with actual use, because there certainly are some (partly) inactive accounts. Therefore, more differentiated usage studies would be needed. Existing studies provide only first insights into the diffusion of SNS among 
scientists and students (Koch and Moskaliuk 2009; Kleimann et al. 2008; Procter et al. 2010; Bader et al. 2012): They generally show a rather low active usage, although the diffusion appears partly higher among young academics. The outcomes of such studies also vary depending on the exact target group and design of the surveys. We may expect that the proportion of SNS users among scientists will increase as the younger generations move up in academia.

We observed the following types of activity levels and usage intensities and propose to differentiate usage in future studies accordingly:

1. Me-too presence: Rudimentary profile; only occasional contacts and never, or only sporadically, become active-probably the most frequent case.

2. Digital calling card: More detailed profile like a type of additional personal homepage; practically no further activity-probably the second most frequent case at the moment.

3. Passive networking: Searching the network in the beginning and thereafter in irregular intervals for other (previously known) members, reacting to automated suggestions to contact other users, sporadic communication with other members.

4. Active networking and communication: Being regularly online, using further services, such as publication search, and participating in group forums, actively searching for potential networking partners beyond those they already know.

5. Cyberentrepreneurship (Nentwich 2003, 175ff.): Not only active participants in the network, but also serving as moderators or animators of group forums, administering groups, are in charge of institutional profiles, giving feedback to the site developers-obviously the rarest form of participation of researchers in SNS.

These are certainly ideal types and in practice appear mixed. We observed repeatedly the above usage types, but cannot offer results regarding their precise empirical distribution. There may also be activities which are not observable from an outside perspective, e.g. private messaging. In any case we need to consider that the activity levels and usage types vary considerably. Consequently, member counts do not lead to insights into the vitality of a SNS. This is confirmed by the study of Procter et al. (2010) on the scientific use of Web 2.0: only $13 \%$ of the participants fall into the category "frequent users", $45 \%$ are "occasional users", and $39 \%$ do not actively use Web 2.0. A large qualitative study with 160 interviews and focus group discussions with US researchers (Harley et al. 2010) notes that SNS are not widely used in academia, with some exceptions.

Despite impressive and growing member counts, we may nevertheless draw the conclusion that SNS are not yet part of the academic mainstream. Given the theoretical potential (see above) we hypothesize that the trend will presumably continue in the future. On the question as to whether scientific SNS may reach the tipping point, see the section "The Hard Way to the Critical Mass". 


\section{Academic Usage Practices in Science-Specific SNS}

Many academics have become members of multi-purpose SNS, such as Facebook, LinkedIn, and Xing, not least because they are widespread and accepted. Usage practices are heterogeneous because these SNS are not particularly focused on academic users; among them we found communication with colleagues, e-teaching, public relations of research institutes, and self-marketing, as well as job exchange. While we have analyzed those practices elsewhere in more depth (Nentwich and König 2012, 38ff.) —our main conclusion being that general SNS play a minor role in the practice of research communication as of yet-we focus in this chapter on science-specific SNS.

We found the following main practices:

Communication and cooperation: One specific strength of science-specific SNS could be their potential to support communication and cooperation among researchers. We did not observe, however, many efficient and successful working groups in these SNS as of yet (they may, however, exist, but are hidden from outsiders). A few self-experiments in our own area have been only modestly successful. They mainly failed because of a lack of potential cooperation partners inside the chosen SNS as we were not able to motivate all relevant colleagues to actively participate in that particular SNS. In contrast to the attraction of large general SNS, the rather young and small science-specific networks suffer from a lack of sufficient numbers of active users (see the section "The Hard Way to the Critical Mass"). In addition, we observed the following further obstacles: technical limitations, lacking experience of users, skepticism regarding file security, the need to firstly develop a common culture of online collaboration, and, finally and notably, the problem of multiple channels (see the section "Multiple Channels, Information Overload and Filtering").

Public relations and self-marketing: Because of their limited target group (mainly peers), these SNS are of limited use for public relations, as you can hardly reach larger groups outside of the science communities in question. In contrast, it is potentially easier to target workers in particular fields by means of the sophisticated mechanisms for networking that most SNS provide. Similarly to general SNS, self-marketing is also possible in science-specific SNS when focused on one's peer group, for example, by drawing attention to one's own publications. Based on our observations, this is currently probably the most widely used activity. There is already a very high coverage of publications in certain fields in SNS like Mendeley (Li et al. 2011; Bar-Ilan 2012).

E-teaching: We did not observe that science-specific SNS are frequently used in teaching. There are specific functions to support it, for instance in research.iversity, but there is not much known yet about their actual usage. Obviously, these professional networks do not seem particularly attractive to students, in contrast to Facebook and other general SNS, because they fit less well with their day-to-day needs and more with the workaday life of a scientist. Hence, students are hardly reachable via this channel, except in experimental settings. However, certain 
effective student-orientated platforms exist, for example Carnets2 Descartes at Paris Descartes University. In any case, SNS may turn out being a good platform for exchange among teaching scientists when they prepare their courses.

Job exchange: These services have the advantage of having a preselected target group in science-specific SNS as opposed to general ones. In September 2012, for example, we found more than 1.000 job offers on ResearchGate, mainly from biomedical enterprises, and some 130 on Academia.edu. The extent to which these job exchanges are actually used is unknown to us.

\section{Assessing the Potential Future and Impacts of SNS in Academia}

Will ever more and, perhaps at some point, most academics use SNS as they use e-mail today? What consequences may this have? In order to answer these questions, we will focus on the following puzzles: How important are network effects and will science-specific SNS reach the tipping point (section "The Hard Way to the Critical Mass")? What role will the very big players play in that game (section “The Hyper-Critical Mass: Too Big to Fail?")? Is the necessity to observe multiple channels in parallel possibly dysfunctional for science communication and will the trend towards multi-functionality and one-stop-services generate the necessary network effects (section "Multiple Channels, Information Overload and Filtering")? And finally (section "Social Issues"): What potential do SNS have for informal communication among academics, and with what effects? What roles do identity, pseudonymity, and anonymity play in scientific SNS? Which privacyrelated conflicts occur?

\section{The Hard Way to the Critical Mass}

Unlike many other Internet technologies, SNS necessarily require a certain critical mass of active users to be functional. This leaves them in a dilemma: They are only attractive with users, but users only come when they are attractive. SNS providers use different strategies to overcome this issue. Of course, they try to develop an infrastructure which is at least potentially useful once their target group has populated the platform. This might attract a number of early adopters who will eventually lure further users until a critical mass has been reached. While this strategy has worked for many Internet start-ups, it is not easily applicable for SNS. The problem here is that new members will only understand the early adopters' attraction once they have built up their own networks within the platform. Therefore, the effective usage of SNS requires a critical mass of users both on a global and also on an individual level. Even a highly populated platform can be dysfunctional for a single user if it does not represent people from his individual 
network or potentially relevant users for future interactions. Building individual networks takes time and effort, while the possible benefits of such an investment are not immediately clear to new users. This might be one of the reasons for the hesitant scholarly usage of SNS.

Another strategy to reach a critical mass can be to minimize the "mass" by addressing a smaller and thus easier reachable target group. Facebook can be seen as a successful example here, as it first aimed only at the Ivy League universities before it was opened up for larger audiences. Carnets2 Descartes is a popular example from the academic realm, focusing on students at the Descartes University in Paris. Although we are not aware of plans to reach beyond this circle, this example shows how a platform can become relevant for a limited audience. Another possible limitation for the academic realm is of course the focus on specific disciplines or even smaller thematic or organizational entities, as it is done by a number of academic SNS. However, smaller target groups can hardly be seen as a general way to success. For example, once the market leader of SNS in Germany, StudiVZ is now struggling with vast numbers of users migrating to Facebook. One reason for this is probably that it failed to address an international audience-in contrast to its main competitor.

Finally, a critical mass of scholars using SNS might be achieved by creating extrinsic incentives. Indirectly, this could be done with altmetrics which extend academic impact assessment beyond the established scientometrics by tracing SNS activities. If relevant institutions acknowledge scholarly engagement on these platforms via such measurements, it would certainly increase the participation of academics in SNS. Directly, incentives could be created by faculties and universities themselves: To a large extent, it is in their hands as to which software should be used for the various researching and teaching activities.

Evidently, such incentives need to be designed carefully and can easily result in unwanted consequences. For instance, altmetrics might get manipulated by "buying" friends, comments, recommendations, etc. There are already numerous companies offering such services for commercial users, which could in principle be used for academic users as well. Also, scholars or students could revolt against being pushed into SNS by their organizations. In particular, Facebook with its privacy issues seems problematic here. Indeed, there were reports on students rejecting approaches on Facebook from their university libraries due to privacy concerns (Connell 2008; Mendez et al. 2009). This points us to another issue: While SNS are undoubtedly dysfunctional without a critical mass, the mass itself can become problematic when it reaches a certain size.

\section{The Hyper-Critical Mass: Too Big to Fail?}

Often Facebook is compared to nations or even whole continents in order to illustrate its massive size. Indeed, the platform does not only outnumber most countries' populations, but also has an enormous economic power and impact on 
various realms of modern societies. Therefore, one could argue that Facebook has not just reached the critical mass to survive, but a hyper-critical mass, overpowering its competitors. While the concentration of users in principle serves the functionality of a SNS and thereby also its users, the power which is accumulated in this way has to be critically observed. On a general level, this has been already a subject of intensive public as well as academic debates which we cannot discuss here in detail. The main concern seems to be privacy-related: Facebook gathers vast amount of data about personal lives and gives its users only very opaque options to control what can be seen by others, including external companies which may have access to this data. This is also a major obstacle for the academic usage of Facebook. On the one hand, the technical hurdle for the academic usage of Facebook is very low for users who already apply the platform for their private lives on a daily basis. On the other hand, this may be exactly what holds them back if they do not wish to blend their professional and their private lives in this way. At the same time, some researchers are reluctant to disseminate work in progress as they feel it is imperfect or because they fear competitiveness (Harley et al. 2010, p. 13). Although this is a general issue of academic social media usage, it is particularly pressing when a company's business model depends on the exploitation of user data as in the case of Facebook or Google.

Moreover, once a SNS has reached a hyper-critical mass, it creates new dependencies, as it works like a black hole: The bigger it gets, the more people are drawn to it, the more content is produced, and so on. Therefore, it becomes increasingly difficult to separate from it. A lot of time has been invested in learning to operate the platform, building networks, discussing issues, editing profiles, creating publication lists, tagging items, etc. Most of this data and effort cannot easily be extracted and imported into another platform, so the hurdle to leave it becomes higher and higher, especially if it is still frequently used by other relevant communication partners. Then it may be (perceived as a) significant part of an individual's or organization's social capital, leading to low mobility of users from social network sites with a hyper-critical mass, creating a self-stabilizing force in turn. This partially explains the "seductive power" (Oosthuyzen 2012) of such sites, making users stay even if they do not agree with its policies or are unsatisfied with its services. At the same time, it is very difficult for alternative SNS providers to compete with this accumulated power which also attracts third-party services like apps.

So, although the functionality of a SNS is increased when it concentrates a vast number of users, such a monopoly-like market situation comes at a price. In the academic context, this is particularly troubling when the SNS is outside the influence of the academic realm. Commercial providers like Facebook do not only have a questionable privacy policy, they also hardly let users participate in the platform design - especially when it comes to such specific needs as scientific ones. Science-specific SNS are more likely to take this into account but they are still mostly in the hand of companies who ultimately decide about the platform's design, policy, and existence. The worst case scenario is, of course, that a service is shut down because it is not profitable or does not fit anymore to a company's 
strategy. This is not just a hypothetical scenario: For instance, users of the blogging and networking platform Posterous could only helplessly witness as the company was acquired by its competitor Twitter, apparently just to let it die slowly and benefit from its staff's competence. In principle, this dependency also applies to non-commercial developers, although they are less driven by the needs of paying clients. They also might change their business model, as it was done in the case of Couchsurfing or StudiVZ, both SNS which started as non-profits but were later commercialized. Therefore, academic institutions should choose a platform carefully if they plan for a sustainable organized engagement. This may be challenging as a platform with a hyper-critical mass can be tempting, especially because of the difficulties in reaching a critical mass on competing platforms.

\section{Multiple Channels, Information Overload and Filtering}

The current status of SNS in the scholarly realm is confusing: As pointed out above, there is no clear market leader with a sufficient critical mass of active scientists yet. Therefore, interested scholars are confronted with multiple potential platforms that they can choose from. Establishing and maintaining various SNS profiles is a time-consuming task, so most academics will rather select only one or a few than be active on various platforms at the same time. This means that the potential scholarly SNS users are spread over numerous services, instead of concentrating on one or two. At the same time, the present "cyberscientists 2.0" who actually use various platforms simultaneously have to face the challenges of these multiple channels: Maintaining their presences already becomes a timeconsuming task under these circumstances. Partly, interoperability across different platforms via APIs solves this problem. For example, a number of social media tools allow the sending of one status update to several platforms. Yet such options are still very limited and not supported by all SNS. Due to the competition between the providers, it is unlikely that this will change fundamentally soon. Apart from maintaining multiple profiles, cyberscientists 2.0 also need to observe diverse channels. Even within one platform this can be a confusing task: Communication takes place in many virtual locations, e.g. via messaging, chatting, group conversations, or commenting. So far, SNS hardly provide options to effectively organize this stream of information, especially when it comes to archiving and retrieving older bits of communication. At the same time, the ongoing news stream via multiple channels can easily overwhelm SNS users, resulting in an information overload. Although the fear of such an information overload was already expressed decades ago (Toffler 1970), some Internet critiques regard this as a pressing issue of the fragmented and hyperlinked structure of the WWW, possibly swamping our neuronal capacities and hindering deeper and coherent thoughts (Carr 2010; Schirrmacher 2009; Spitzer 2012). Moreover, we need to remember that SNS only add up to the already existing communication channels-from other social media platforms to e-mail, telephone, and many more. 
Partly, users will cope with the challenge of information overload by developing specific strategies. For example, they may limit their practices to intentional active usage, which is less likely to lead to endless distraction through non-targeted passive usage. One could also argue in favor of SNS that one of the main ideas of these services is an effective information selection by people who we trust. However, as soon as one's digital social network reaches a certain size, it becomes extremely time-consuming if not impossible to follow it. Then additional filter mechanisms are needed. In sophisticated platforms these are organized in the background through algorithms hidden from the user. While this creates additional opacity, the selection of information through peers within SNS per se leads to an individual bias depending on one's networks. The common argument in favor of this novel way of personalized gatekeeping is that it is more likely to deliver content which is relevant to the user. Critiques, however, fear it will lead us into a distorted "filter bubble" (Pariser 2011), lacking diversity and serendipity. In the first place, this is a concern for the public sphere. Yet we may also wonder what impact these new filter mechanisms will have upon the academic realm. Will this work against the general tendency of blurring (disciplinary) boundaries in the context of fluid digital networks? Might this re-define scholarly relevance and visibility to a certain extent? Will new metrics such as ResearchGate's RG Score (see Fig. 1 above) one day become serious competition for established scientometrics? On the one hand, the current low penetration of SNS into the academic sector does not make these questions appear very urgent. On the other hand, these questions are highly relevant to those scholars who already use the emerging platforms. They change the way scientists interact and exchange information. Since this differs according to the individual digital networks and the phenomenon has not yet fulfilled its whole potential, one can hardly draw broader conclusions on the exact impact of these developments at this point.

\section{Social Issues}

Informal Academic Communication 2.0. By offering multiple electronic paths to reach and chat with members of the research community, SNS increase the possibility and likelihood of informal communication. Fully-fledged Cyberscience 2.0 - or Science 2.0 - would certainly look different to today's interim state-ofaffairs. It may be characterized by massive, ubiquitous, possibly transdisciplinary micro-communication among academics, and with interested lay observers (Nentwich and König 2012, p. 200f.). This is already happening in certain niches with very active academic cyberentrepreneurs, but it is anything but the norm as of yet. It will be interesting to see what impact this may have on the structure of the science system as it becomes more common. We may also ask whether SNS may contribute to formalize the informal by making social networks of researchersthe so-called "invisible colleges" (Crane 1972)—more transparent. Depending on 
factors like privacy settings and the chosen communication channels, SNS partly reveal who is connected to whom and how closely.

The Ambiguous Roles of Identity, Pseudonymity and Anonymity. With regard to private use of SNS, pseudonymity instead of having a profile with one's real identity is frequently practiced, though discouraged. Thus it is possible to differentiate between different roles. Anonymous accounts are usually not possible. By contrast, in professional SNS which often also serve as public calling card directories, pseudonymity would be counter-productive because the users need to get in touch with "real" people. Similarly, pseudonymity is mostly dysfunctional in academia. Science communication rests on the premise that you communicate, whatever the medium, with actual persons in order to be able to cooperate or coauthor. In other words, merits need to be attributable: researchers definitely expect that behind a profile in a SNS is another researcher who has actually written the papers listed in the publications attached to the profile. Some SNS try to guarantee this by verifying the identity on registration (e.g. BestThinking). In most cases, researchers also desire to be recognized in order to better establish themselves and increase their reputation. However, there are two cases where temporal or functional anonymity is in the interest of academia: In many fields, the peer-review process is usually double-blind. We may conceive that also the various rating systems within SNS, most of which are not anonymous as of yet, may be implemented in a way that allows anonymous rating. The other case is when it comes to testing new ideas in a creative forum space or during collective brainstorming. Here it may fuel creativity when the relation between callow thoughts and the originator would not be registered permanently in a written archive. For many cases, it seems desirable to create several personal "micro-publics" which may overlap, but "allow for distinct foci" (Barbour and Marshall 2012), e.g. in order to address different fields and audiences, such as peers and students.

Is Privacy an Issue in SNS? Mixing private and professional roles is an obvious problem in general SNS (like Facebook) which almost inevitably blend both identities. This is less so in science-specific SNS where the related privacy conflicts are attenuated: We observed that most researchers reveal only their professional identity here. This is usually supported by the set of information one is supposed to enter when setting up one's profile: the forms ask for biographical information relevant to academia and less for private facts such as relationship status. Note, however, that even ResearchGate asks for pet books and hobbies, but only receives answers from a few according to our observations. In any case, people using SNS leave their digital marks and traces, and so do researchers. There is currently an intense discussion about privacy concerns in the general SNS. At least some of researchers' reluctance to join SNS may be explained by fear of losing control over their privacy. In science-specific SNS, the data needed to enable efficient networking based on automatically generated suggestions is to a very large extent professional in nature, such as curriculum vitae, publications, research interests, office contact information, etc. Nonetheless, if researchers are very active on various Web 2.0 platforms, they create significant digital traces that can be analyzed by data-mining tools. Identity theft (OECD 2008) is another 
salient issue. Profiles may be hacked with the intention of damaging somebody's reputation, or false identity may be assumed in order to gain some benefits. Barbour and Marshall argue that under these circumstances it is better to actively shape one's online persona than leaving this to others:

\begin{abstract}
Although many academics do contribute to their online persona creation, there are just as many who do not engage with new media in any meaningful way. However, this does not mean that they are not present online. The risk of not taking control of one's own online academic persona is that others will create one for you. This is what we are terming the 'uncontainable self' (Barbour and Marshall 2012).
\end{abstract}

\title{
Conclusions
}

A close look at the technical functions of SNS shows that they are potentially useful for a number of scholarly activities. In fact, they offer so many services that they theoretically may serve as an encompassing platform, quasi a "one-stopservice 2.0" of use for all major tasks within academia-from knowledge production and distribution to communication and, even beyond the borders of academia's ivory tower, for public relations and other connections between science and its environment. A large-scale implementation of SNS would imply a number of major changes compared to the way scientists interact today. To begin with, it would diversify the possibilities for interaction, creating a number of fragmented pieces of information. Every single SNS does that due to the multiple channels that it provides. The currently unclear market situation in the field of science-specific SNS enforces this effect, since it creates even more channels. One could argue that this might also lead to social diversification of academia, as it comes with new possibilities for networking and increased transparency, including novel perspectives for informal communication. It may become visible with whom researchers interact with, what they read, discuss, and consider important. What is more, other researchers from various fields and positions, even students and lay people, might participate in these interactions. This tendency of lowering statusbased communication hurdles might be regarded as democratization of science. Some would even argue that this would increase the quality of scientific work, as it may be checked by more peers in an ongoing process that is much faster than the regular circles of peer-reviewing.

However, we believe that these assumptions are far-fetched given the current state of affairs. The diffusion of SNS in academia is still fairly low and even lower when we focus on active scholars who make full use of the potential of these platforms. As pointed out above, this is crucial for SNS because their whole purpose is to create connections between active users. This limits the general potential of SNS, no matter whether one sees it as desirable or problematic. Even with today's rather low participation, it is obvious that the vast amount of fragmented information distributed via multiple channels can quickly become 
dysfunctional and lead to information overloads. This will rather work against democratizing effects as scientists (or automated filter mechanisms) will have to limit their attention even more-most likely to already well-established scholars and channels. The transition to (Cyber-)Science 2.0 is to a large extent driven by younger academics who may partly benefit in this context as they often know "how to play the game" of Web 2.0 better than their more senior colleagues. For example, it is not unlikely that a young researcher will be rated higher by a novel SNS-based metric like the RG Score. However, this advantage will probably diminish if such numbers gain importance for evaluations. However, as long as altmetrics still play a minor role, it is anyway questionable how much such a benefit is really worth. In fact, it may even lower the status of a researcher because others might regard the active usage of SNS as a waste of time.

Despite all of these difficulties, especially with regard to reaching the tipping point of enough scientists actively using SNS, these services appear to be on the rise. Since a critical mass of users can turn into a hyper-critical mass-which in itself is problematic_we should make use of the opportunities of this current transition period. Academics can (and should) shape future developments instead of leaving it to commercial providers who follow their own interests. Coming back to the title of this contribution: Academia might indeed "go Facebook" if it does actively interfere by providing and further developing independent platforms. There are already attempts to do exactly that, most-notably vivo, which gives academic institutions a lot of freedom because it is based upon open source software which can be run on local servers. However, it has apparently not reached a critical mass yet and it will take more effort within academia to push such independent projects to the point that they can compete with the temptations of the global Internet players. Of course, commercial platforms may still simply create the better platforms with more engaged scholars and it is debatable as to whether it is desirable to interfere with this. This is very much a political question which can be answered differently, depending on one's point of view. Some will believe in the free market, others will favor an active involvement of scientific institutions and policy-makers, maybe even including regulation.

In the meantime, it seems likely that the unclear market situation in the field of scientific social networks is not going to be clearly solved very soon. Therefore, the best way to increase the functionality of these services is interface harmonization (e.g. via APIs), allowing the various services to connect to each other. There are also academic initiatives in this direction; for example, ScholarLib connects scientific thematic portals with SNS (Thamm et al. 2012). Again, such attempts are limited by the will of the providers to create such openness via suitable APIs. Obviously, we are witnessing a very dynamic development with both a promising potential for the future of science and research-and for reflection.

Open Access This chapter is distributed under the terms of the Creative Commons Attribution Noncommercial License, which permits any noncommercial use, distribution, and reproduction in any medium, provided the original author(s) and source are credited. 


\section{References}

Bader, A., Fritz, G., \& Gloning, T. (2012). Digitale Wissenschaftskommunikation 2010-2011 Eine Online-Befragung. Giessen: Giessener Elektronische Bibliothek. Available at http:// geb.uni-giessen.de/geb/volltexte/2012/8539/index.html.

Barbour, K., \& Marshall, D. (2012). The academic online: Constructing persona through the World Wide Web First Monday. First Monday, 17(9). Available at: http://firstmonday.org/ htbin/cgiwrap/bin/ojs/index.php/fm/article/view/3969/3292.

Beer, D. D. (2008). Social network(ing) sites...revisiting the story so far: A response to danah boyd \& Nicole Ellison. Journal of Computer-Mediated Communication, 13(2), 516-529. doi:10.1111/j.1083-6101.2008.00408.x.

Biermann, K. (2010). Facebook, bing und Skype vernetzen sich. ZEIT Online. Available at http:// www.zeit.de/digital/internet/2010-10/facebook-bing-skype.

Boyd, D. M., \& Ellison, N. B. (2007). Social network sites: definition, history, and scholarship. Journal of Computer-Mediated Communication, 13(1), 210-230. doi:10.1111/j.1083-6101. 2007.00393.x.

Carr, N. G. (2010). The shallows: what the Internet is doing to our brains. New York: W.W. Norton.

Connell, R. S. (2008). Academic libraries, Facebook and MySpace, and student outreach: A survey of student opinion. Portal: Libraries and the Academy, 9(1), 25-36. doi:10.1353/ pla.0.0036.

Crane, D. (1972). Invisible colleges; diffusion of knowledge in scientific communities. Chicago: University of Chicago Press.

Fuchs, C. (2009). Social networking sites and the surveillance society. A critical case study of the usage of studiVZ, Facebook, and MySpace by students in salzburg in the context of electronic surveillance. Salzburg/Wien: ICT\&S Center (University of Salzburg), Forschungsgruppe Unified Theory of Information. Available at http://twinic.com/duploads/0000/0509/ ICT_Use_-_MySpace_Facebook_2008.pdf.

Harley, D., et al. (2010). Assessing the future landscape of scholarly communication: An exploration of faculty values and needs in seven disciplines. Berkeley, CA: Center for Studies in Higher Education.

Bar-Ilan, J. (2012). JASIST@mendeley. In ACM Web Science Conference 2012 Workshop. Evanston, USA. Available at http://altmetrics.org/altmetrics12/bar-ilan/.

Kleimann, B., Özkilic, B. \& Göcks, M. (2008). Studieren im Web 2.0. Studienbezogene Webund E-Learning-Dienste. Hannover: HIS Hochschul-Informations-System GmbH. Available at https://hisbus.his.de/hisbus/docs/hisbus21.pdf.

Koch, D., \& Moskaliuk, J. (2009). Onlinestudie: Wissenschaftliches Arbeiten im Web 2.0. Elearning and education. Eleed, 5. Available at http://eleed.campussource.de/archive/5/1842.

Li, X., Thelwall, M., \& Giustini, D. (2011). Validating online reference managers for scholarly impact measurement. Scientometrics, 91(2), 461-471. doi:10.1007/s11192-011-0580-x.

Mack, D., et al. (2007). Reaching students with Facebook: Data and best practices. Electronic Journal of Academic and Special Librarianship, 8(2). Available at http:// southernlibrarianship.icaap.org/content/v08n02/mack_d01.html.

Mendez, J. P., et al. (2009). To friend or not to friend: Academic interaction on Facebook. International Journal of Instructional Technology and Distance Learning, 6(9), 33-47.

Nentwich, M. (2003). Cyberscience: Research in the age of the Internet. Vienna: Austrian Academy of Sciences Press.

Nentwich, M., \& König, R. (2012). Cyberscience 2.0: Research in the age of digital social networks. Frankfurt, New York: Campus Verlag.

OECD, 2008. Scoping Paper on Online Identity Theft, Seoul: Organisation for Economic Cooperation and Development. Available at: http://www.oecd.org/dataoecd/35/24/40644196.pdf. 
Oosthuyzen, M. (2012). The seductive power of Facebook. Unlike us blog. Available at http:// networkcultures.org/wpmu/unlikeus/2012/05/24/the-seductive-power-of-facebook.

Pariser, E. (2011). The filter bubble what the Internet is hiding from you. New York, USA: Penguin.

Procter, R., Williams, R., \& Stewart, J. (2010). If you build it, will they come? How researchers perceive and use Web 2.0. Research Information Network. Available at http://www.rin.ac.uk/ our-work/communicating-and-disseminating-research/use-and-relevance-web20-researchers.

Richter, A., \& Koch, M. (2008). Funktionen von Social-Networking-Diensten. In M. Bichler et al. (Eds.), Multikonferenz Wirtschaftsinformatik 2008 (pp. 1239-1250). Berlin: GITOVerlag. Available at http://ibis.in.tum.de/mkwi08/18_Kooperationssysteme/04_Richter.pdf.

Richter, A., \& Koch, M. (2007). Social software—status quo und Zukunft. München: Fakultät für Informatik, Universität der Bundeswehr München. Available at http://www.unibw.de/ wow5_3/forschung/social_software.

Schirrmacher, F. (2009). Payback warum wir im Informationszeitalter gezwungen sind, zu tun, was wir nicht tun wollen, und wie wir die Kontrolle über unser Denken zurückgewinnen. München: Blessing.

Schmidt, J. (2009). Das neue Netz: Merkmale, Praktiken und Folgen des Web 2.0. Konstanz: UVK Verlagsgesellschaft.

Spitzer, M. (2012). Digitale Demenz: wie wir uns und unsere Kinder um den Verstand bringen. München: Droemer.

Thamm, M., Wandhöfer, T., \& Mutschke, P. (2012). ScholarLib-Ein Framework zur Kopplung von Sozialen Netzwerken mit wissenschaftlichen Fachportalen. In M. Ockenfeld, I. Peters, \& K. Weller (Eds.), Social Media and Web Science das Web als Lebensraum; 64. Jahrestagung der DGI, Düsseldorf, 22. bis 23. März 2012; Proceedings (pp. 205-212). 2. DGI-Konferenz, 64. Jahrestagung der DGI. Frankfurt a. M.: DGI.

Toffler, A. (1970). Future shock. New York: Random House. 